\title{
Approach to the choice of modernization directions for the system of geodynamic monitoring in cases of using components intensity uncertainty
}

\author{
O.R. Kuzichkin', V.T. Eremenko ${ }^{2}$, I.V. Loginov ${ }^{3}$, A.V. Eremenko ${ }^{4}$, S. V. Eremenko ${ }^{5}$, A.V.Grecheneva ${ }^{6}$, \\ G.S. Vasilyev ${ }^{7}$ \\ 1,6,7 Belgorod State University, Russia \\ 2,3,4,5 Orel State University, Russia
}

\begin{tabular}{l} 
Article Info \\
\hline Article history: \\
Received, Jul 24 2019 \\
Revised Sep 26, 2019 \\
Accepted Oct 11, 2019 \\
\hline Keywords: \\
Evolution \\
Geodynamic monitoring system \\
Modernization \\
Ranking \\
Requirements system \\
Resource effect \\
Resource intensity \\
Uncertainty
\end{tabular}

\begin{abstract}
The problem of the optimum choice of the modernization directions for geodynamic monitoring systems, which is solved in the conditions of changing the parameters of natural-technical systems (NTS) is considered in the work. The solution of the task is creating a list of the components modernization directions and validate ranking the most effective of them. As criterion of modernization the value of decrease in resource intensity of subsystem application is using. The task is considering the uncertainty of quantity of the arriving tasks. Within the suggested method, it is offered to determine the effect of resource by each modernization direction. The functional dependences on its increase depending on an expense of resources of modernization. The decision is reached by minimization of total cost of modernization resources for the system in the conditions of change using components intensity at change of external conditions.
\end{abstract}

Copyright $\odot 2020$ Institute of Advanced Engineering and Science. All rights reserved.

\section{Corresponding Author:}

O.R. Kuzichkin,

Belgorod State University,

85 Pobedy St, Belgorod, Russia.

Email: esfehani.mohamad3@gmail.com

\section{INTRODUCTION}

The development of geodynamic monitoring system, such as distributed information and communication systems and environments, is implemented through the modernization activities. For geodynamic monitoring system, it is possible to simultaneously implement a significant number of modernization projects, the results of which change the efficiency of the system. A large number of alternative directions of modernization and the limited resources allocated to development determine the need to plan development programs by selecting the best direction and determining the amount of resources allocated to them. Currently, the problem being solved by expert development programming does not fully take into account the possibility of optimal allocation of resources with the uncertainty of the components using intensity. Thus, the problem of developing a method of choosing the directions of modernization and the distribution of limited resources between them under the conditions of uncertainty of the components using intensity are actualized now. 


\section{THE REVIEW OF APPROACHES TO THE CHOICE OF MODERNIZATION DIRECTIONS FOR A MONITORING SYSTEM IN CASES OF USING COMPONENTS INTENSITY UNCERTAINTY}

The need to develop geodynamic monitoring systems due to changes in the levels of exogenous and endogenous effects on the TCP determines the need for a rational choice of areas of modernization and the allocation of resources allocated for modernization between them. To solve this problem, a mathematical apparatus has been formed that implements the determination of the order, methods and methods for managing the development of monitoring systems [1-4]. The classification and review of the main approaches used in the analysis, design, implementation, and modernization of monitoring and control systems is given in [2]. For complex planning of modernization of automated systems of the class of information and communication media, the provisions of the theory of control of the structural dynamics of complex systems can be applied [3]. The method proposed in [3] allows implementing the optimal choice of programs for the development of complex technical systems from a set of alternatives. When solving the problem of improving the quality of automated process management using the facts of finding "bottlenecks", the provisions of the theory of constraints [1] are applied. The essence of using the theory of constraints is to optimize management and resources by distributing applications based on the status of their implementation.

When solving problems of development of information and communication environments, it is necessary to consider changes in the external environment. A variant of accounting for such changes is the methodology [5], the main provisions of which are to combine a formalized business strategy in the field of information and telecommunication systems and patterns of strategic behavior based on patterns. A pattern is understood as the combination of decision-making methods on the implementation of alternative areas of modernization, measuring the effect and the method of supporting adaptability.

In hierarchical systems, issues of modernization are considered taking into account complex effects. Synthesis of optimal structures can be realized on the basis of linking the goals of the strategic and operational level using graph models [6], hierarchical systems of a heterogeneous network structure [7].

Expert application of alternatives [8-9] has found widespread use in choosing areas of modernization. In this case, the streamlining of modernization directions is implemented according to a system of criteria. In the literature [10-11], both methods for determining the system of criteria and methods for determining the weights of particular indicators using expert methods are widely considered. In the process of expert choice are used: methods of analyzing hierarchies, methods of analytical networks, multicriteria analysis, mathematical optimization [10,12-13]. Expert assessment methods differ in the types of estimates of particular indicators used.

If it is possible to represent a monitoring system in the form of a set of automated processes, this task is solving by optimal processes reengineering method. By system reengineering the architecture of process and tools automation are transform. Hierarchical, divisional, sequential, and service-oriented forms are used for designing process architectures [14]. For the development of subject area ontologies for processes reengineering the methods of ontological reengineering and reference ontologies of business processes of communication enterprises are created [15]. Transformation tasks of organization processes with software using are considered: business implementation methodology [16], lean six sigma L6S-Tesco [17].

The analysis of the applicability of management and development planning methods, including the modernization of monitoring system s, indicate the need to account the uncertainty of the components using intensity. Dynamic changes of requirements are considered to take into account the uncertainty factor of time changes of requirements systems [18-19]. Information is used not only about the uncertainty of the values of factors, but also the change in the amount of uncertainty depending on the conditions of decision-making under risk [20]. Known methods [21], used for ranking the alternatives of modernization directions by systems of requirements are divided into linear and nonlinear models of weight coefficients; categorical models; weighted point models; models of total cost of ownership; adapted models, built using the methods of neural networks and the main component; models of the theory of multidimensional utility. The fuzziness of many factors determines the application of fuzzy model. Accounting for the uncertainty of the initial data involves the use of factor estimates in various scales and types of estimates: point, interval, probability, fuzzy estimates, ranks [10, 13, 22-27].

The ability to select several modernization directions with the resources allocation between them requires the solution of optimization problems. Thus, in the conditions of uncertainty of the using intensity, additional optimization effects should be taken into account by the different efficiencies of individual directions. 


\section{THE PROBLEM OF OPTIMAL CHOICE OF MODERNIZATION DIRECTIONS FOR MONITORING SYSTEMS UNDER THE INTENSITY OF ITS USE UNCERTAINTY}

The solution of the problem of choosing the modernization directions for a system from a variety of different alternatives for the modernization of its individual components (processes) is considered in the situation of the resources allocated limit. Such system is characterized by many alternatives for modernization, the effect of which depends on the applied organizational and technical solutions. The task of selecting the components to be upgraded is complicated by the uncertainty of changing the resource effect for the components under consideration.

Modernization of a monitoring system is implemented by improving its individual components. The total resources for maintenance of the system functioning are formed by summing the multiplication of the specific resource consumption by the number of the components application cycles. This allows predicting the total cost of resources for the planning period and to resources modernization allocating in accordance with the forecast.

The mathematical problem has the following form:

Known:

a. The complex monitoring system $S$ includes several components $S_{i}$ that can be upgraded: $\left\{S_{i}\right\}, i=(1, I)$

b. For the operation of the system $S$ resources $R_{S}$ are used: $R_{S}=\sum_{i=0}^{I} R_{i}$. The amount of resources used for the operation in the planning period is limited: $R_{S} \leq R^{\text {req }}$. Resources are used on cycles of the components $S_{i}$ using.

c. To modernize the system $S$ resources $R_{M}$ can be used: $R_{M}=\sum_{i=0}^{I} r_{i}$, where ${ }^{r_{i}}$-is the resources for the modernization of the component $S_{i}$ in the planning period. Modernization leads to a change in the resource effect on the cycle of using the system component.

d. Resource effect function $\psi_{i} \in \Psi$, showing the impact of components $S_{i}$ modernization by the allocated resources: $\psi_{i}=\psi_{i}\left(r_{i}\right)$.

e. Based on the analysis of experimental data in accordance with [28], it is determined that the logarithmic function can be used as a type of functional dependence of the increase in resource return on the amount of resources for modernization:

$$
\psi_{i}=\psi_{i, 0} \times \log _{a_{i}}\left(k_{i} \times r_{i}+a_{i}\right)
$$

where $\psi_{i, 0} \in \Psi_{0}$ - the value of the indicator of resource return at the initial time before modernization; $a_{i}$ and $k_{i}$ - parameters that indicate the level of impact of the efficiency of resource consumption on the improvement of the component $S_{i}$. The values of the parameters $a_{i}$ and $k_{i}$ are calculated on the basis of estimates of the effects of the components modernization and the will act in the task as source of data.

f. The number of components to be improved in the planning period $L$.

g. The confidence interval of the accuracy of the optimization problem $\alpha$.

h. Set of cycle's quantities of the components $S_{i}$ using in the source $N_{0}=\left\{n_{i, 0}\right\}$ and in the planning $N=\left\{n_{i}\right\}$ period. The number of usage cycles $N=\left\{n_{i}\right\}$ is uncertain because it is not possible to accurately predict the number of usage cycles. Within the task, the planned number of components $S_{i}$ using cycles is given by a fuzzy triangular number: $n_{i}=\left\langle n_{i, \min } ; n_{i, \bmod } ; n_{i, \max }\right\rangle$.

To find the allocation of resources: $\left.{ }^{{ }} r_{i}\right\}, R_{M}=\sum_{i=0}^{I} r_{i}$ by set of modernized components $S_{i}$ while limiting the amount of the shared resource $R_{S}$ is not above required: $R_{S} \leq R^{\text {req }}$. The change in resource requirements for the operation of the system without its modernization is positive: $\Delta R=R_{S}-R_{S, 0}>0$. 


\section{THE METHOD OF RESOURCES ALLOCATION BETWEEN MODERNIZATION DIRECTIONS FOR A MONITORING SYSTEM IN THE CASE OF THE UNCERTAINTY IT'S PLANNED USE}

The essence of the method is to use the fact that the maximum efficiency of allocation resources $R_{M}=\sum_{i=0}^{I} r_{i}$ on improving the set of components $S_{i}$ is achieved when the marginal effects of reducing their resource intensity are equal: $\Delta R_{i} / \Delta r_{i} \rightarrow$ const . Accordingly, the search for such subset of components $S_{i}$ the amount of resources for their modernization $R_{M}=\sum_{i=0}^{I} r_{i}$, which would compensate the increase in resource intensity due to the increase in the number of the system using cycles $N=\left\{n_{i}\right\}$, are suggested.

Changing the number of the system components $S_{i}$ using cycles $N=\left\{n_{i}\right\}$ leads to a change in the resource requirements $R_{i}$ for their operation. Changing resource requirements can be found by summarizing the changes across all components:

$$
\begin{aligned}
& \Delta R=\sum_{i=0}^{I} \Delta R_{i}=\sum_{i=0}^{I} R_{i}-\sum_{i=0}^{I} R_{i, 0}, \text { where } \\
& R_{i, 0}=\frac{n_{i, 0}}{\psi_{i, 0}} \\
& R_{i}=\int_{n_{\min }}^{n_{\max }} \frac{\beta_{i}(n) n}{\psi_{i, 0}} d n
\end{aligned}
$$

where $\beta_{i}(n)$ - the probability density function for number of the system components ${ }^{i}$ using cycles in the planning period.

Due to the modernization of the components $S_{i}$ it is possible to reduce resource requirements due to increased resource efficiency $\psi_{i}$. In this case, the change in resource requirements can be calculated by the formula:

$$
\Delta R=\sum_{i=0}^{I} n_{i}\left(\frac{1}{\psi_{i, 0}}-\frac{1}{\psi_{i}}\right)
$$

Within the proposed method for all modernization directions (for each component of the system ${ }{ }_{i}$ ) the function of reducing the resource intensity of the component $g_{i}$ is calculated. It shows how the resource intensity of the component maintenance process is reduced in the planned period, taking into account the change in the components using cycles $n_{i}$ and resource efficiency $\psi_{i}$ :

$$
g_{i}=\Delta R_{i}=n_{i}\left(\frac{1}{\psi_{i, 0}}-\frac{1}{\psi_{i}}\right)=\frac{n_{i}}{\psi_{i, 0}}\left(1-\frac{1}{\log _{a_{i}}\left(\mathrm{k}_{i} \times r_{i}+a_{i}\right)}\right)
$$

The maximization of the using resources on the modernization of components $S_{i}$ effect is achieved with the equality of the marginal effects of reducing the components functioning resource intensity $R_{i}$ to the resources of modernization $r_{i}$ for all components:

$$
\frac{\Delta g_{1}}{\Delta r_{1}}=\ldots=\frac{\Delta g_{i}}{\Delta r_{i}}=\ldots=\frac{\Delta g_{I}}{\Delta r_{I}}=\text { const } \Rightarrow g_{i}^{\prime}\left(r_{i}\right)=\text { const }
$$


where $g_{i}^{\prime}\left(r_{i}\right)$ - is the derivative of the of reducing the components resource intensity function $g_{i}$ by modernization resources.

The basic idea of using the expression (7) is explained in Figure 1. In accordance with the expression (1) when adding new resources $r_{i}$ for the modernization of the system component $S_{i}$ the additional effect of reducing the resource intensity decreases: $g_{1}>g_{2}$. Thus, the marginal effect of reducing resource intensity is also reduced: $\frac{\Delta g_{1}}{\Delta r_{1}}>\frac{\Delta g_{2}}{\Delta r_{2}}, \Delta r_{1}=\Delta r_{2}$. Review of several modernization directions for components $S_{i}$ in Figure 1, two directions are reviewed shows that it is possible to fix the limiting effect in one direction $g_{1}(r)$ and find the same target effect in the second direction $g_{2}(r)$. In this case, the most acceptable is the division of resources between the two modernization directions, in which the value of the marginal effect will be equal, since the additional resource expended in each direction brings the same effect of reducing the resource intensity of the component operating:

$$
\frac{\Delta g_{1}}{\Delta r_{1}}=\frac{\Delta g_{2}}{\Delta r_{2}}, r_{1}+r_{2}=R_{M} \Rightarrow g_{1}+g_{2}=\Delta R_{\max } \rightarrow \max
$$

Otherwise (at inequality of limiting effects), the additional effect of decrease in resource intensity of components functioning will be different; respectively the total effect is less than potential:

$$
\frac{\Delta g_{1}}{\Delta r_{1}} \neq \frac{\Delta g_{2}}{\Delta r_{2}}, r_{1}+r_{2}=R_{M} \Rightarrow g_{1}+g_{2}<\Delta R_{\max }
$$

The use of criterion (7) in solving the problems of optimizing the allocation of modernization resources $R_{M}=\sum_{i=0}^{I} r_{i}$ requires finding a derivative for function of reducing the component resource intensity (6):

$$
\begin{aligned}
& g_{i}^{\prime}=\frac{n_{i}}{\psi_{i, 0}}\left(1-\frac{1}{\log _{a_{i}}\left(\mathrm{k}_{i} \times r+a_{i}\right)}\right)^{\prime} \\
& g_{i}^{\prime}=\frac{n_{i}}{\psi_{i, 0}} \frac{1}{\left(\mathrm{k}_{i} \times r+a_{i}\right) \times \log _{a_{i}}^{2}\left(\mathrm{k}_{i} \times r+a_{i}\right)}
\end{aligned}
$$

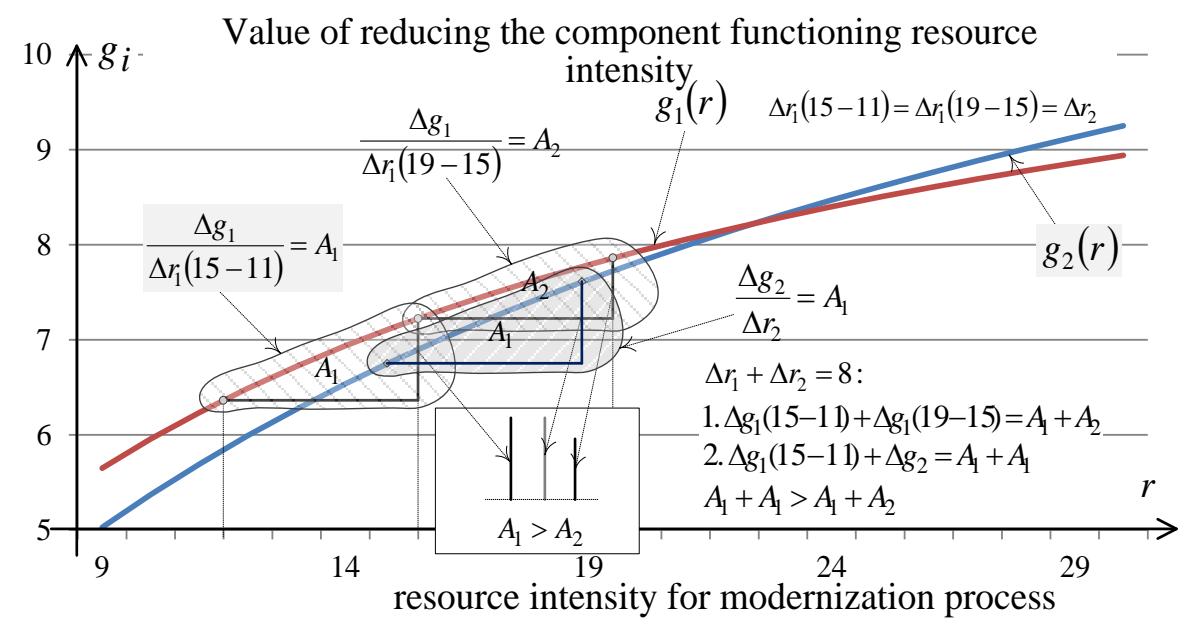

Figure 1. Scheme of the criterion of maximum efficiency of modernization resources allocation 
The task - finding the distribution of modernization resources $R_{M}=\sum_{i=0}^{I} r_{i}$ between modernization directions, is implemented in accordance with the algorithm shown in Figure 2.

The algorithm assume to determinate the intermediate level of the limiting effect of reducing resource intensity $h_{0}$ and calculating in accordance with it for each modernization direction $S_{i}$, the amount of resources required to achieve it $r_{i}$. Based with the $r_{i}$ in accordance with the formula (6), the value of $g_{i}$ for each upgraded component is calculated. The achieved total effect (5), represented by a fuzzy number, is compared with the required: $\Delta R \in\left[R_{S}^{\mathrm{req}}(1-\alpha) ; R_{S}^{\mathrm{req}}(1+\alpha)\right]$. When the limit is reached, the algorithm stops. Otherwise, a new intermediate state $h_{0}$ is calculated. The calculation of the resource requirements to achieve a required level of the limiting effect of reducing the resource intensity $g_{i}^{\prime}(r)=h_{0}$ is carried out by resolving the expression (12) by ${ }_{i}$ with using approximate methods:

$$
\left(\mathrm{k}_{i} \times r_{i}+a_{i}\right) \times \log _{a_{i}}^{2}\left(\mathrm{k}_{i} \times r_{i}+a_{i}\right)=\frac{n_{i}}{\psi_{i, 0}} h_{0}
$$

Finding an approximate solution is achieved by using a gradient method, which allows calculating gradient defined by the following formula:

$$
\gamma=\frac{\sum_{i} g_{i}\left(h_{\min }\right)-\sum_{i} g_{i}\left(h_{\max }\right)}{h_{\max }-h_{\min }}
$$

where $g_{i}\left(h_{\min }\right)$ and $g_{i}\left(h_{\max }\right)$ - the procedures for calculating the values of resource intensity reduction by the maximum $h_{\max }$ and minimum $h_{\min }$ value of the limiting effect of resource intensity reducing $h_{0}$.

The calculation of the new level of the limiting effect of reducing the resource intensity (the value of the derived function $g_{i}^{\prime}$ ), for which the need for resources on components modernization will be calculated at the new step, is carried out according to the following formula:

$$
h_{0}=h_{\min }+\frac{\sum_{i} g_{i}\left(h_{\min }\right)-R_{S}^{\text {req }}}{\gamma}
$$

The solution of the optimization problem assumes to remove from the set of modernized components of systems those processes that value of the increase effect is small (for which $g_{i} \leq 0,001 \Delta R$ ). This is due to the practical inexpediency of dispersing forces and resource in many modernization directions, the improvement of which will not have a significant effect, but will require the allocation of resources. The calculation of changes in resource requirements is accorded to the formula:

$$
\Delta R=\sum_{i} g_{i}=\sum_{i} \Delta r_{i}
$$

The result of the algorithm is the distribution of resources $\left\{r_{i}\right\}$ on a set of components of a monitoring system, that being improved in the planning period. 


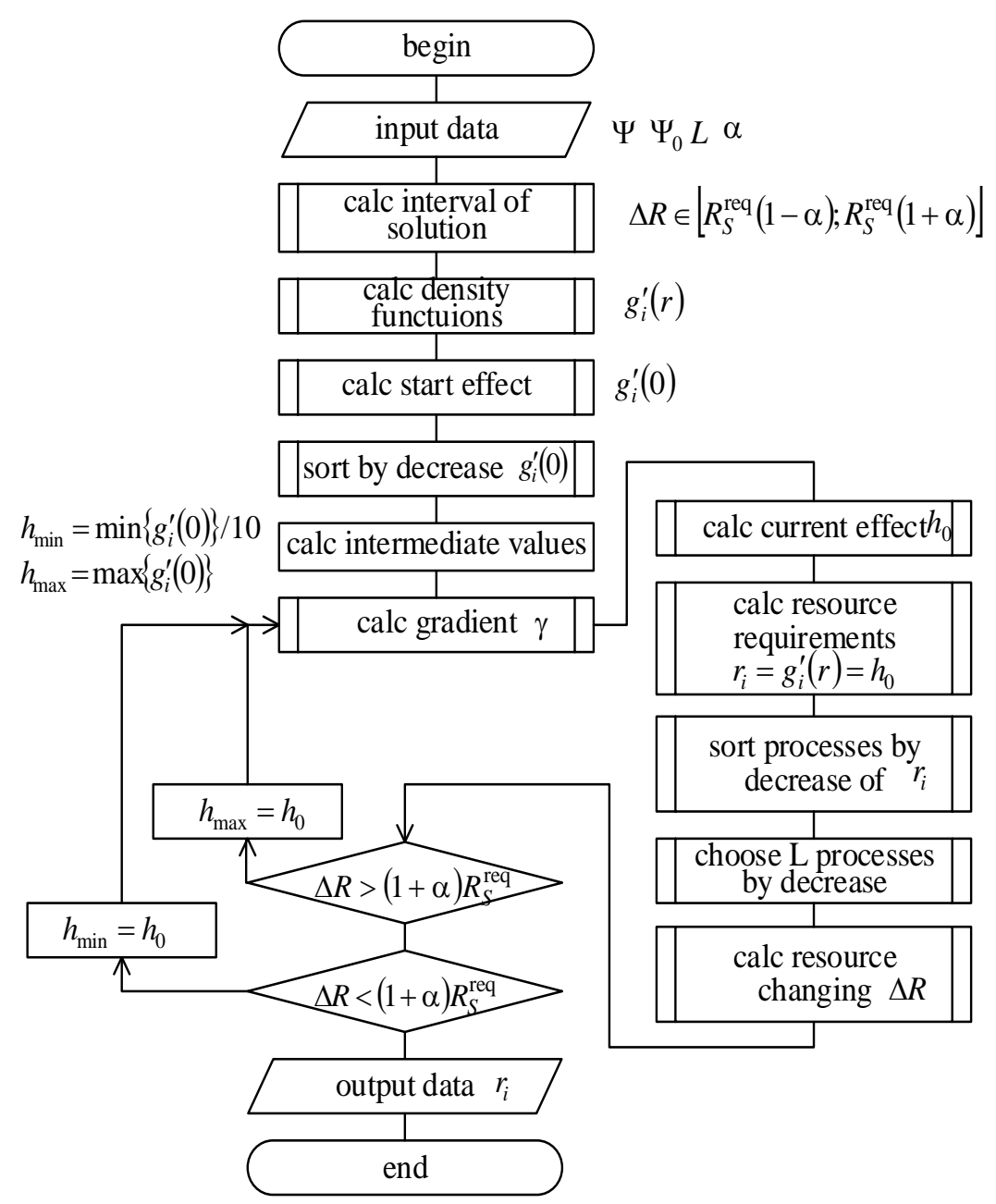

Figure 2. Block diagram of the algorithm for the allocation of modernization resources by directions

\section{THE APPLICATION OF THE METHOD OF RESOURCES ALLOCATION BETWEEN MODERNIZATION DIRECTIONS WITH THE UNCERTAINTY OF THE PLANNED EFFECTS FOR ORGANIZATION IT-INFRASTRUCTURES}

The application of the proposed method to the problem of choosing modernization directions of organization IT-infrastructure are viewed in the article. In managing the development of IT-infrastructure, three major functional blocks (initial automation processes) are pointed:

a. Incident management;

b. Application management;

c. Asset \& configuration management.

Thus it is possible to upgrade three components of a monitoring system : $S=\left\{S_{i}\right\}, i=1 . .3$. Modernization of hardware and software components of these subsystems can reduce labor costs to perform tasks in the framework of the corresponding automated processes. The restriction on modernization actions is to provide the initial resource-intensive operation of the IT-infrastructure, with the changes in the number of applications cycles in the system. The intensity of component utilization $S=\left\{S_{i}\right\}, i=1 . .3$ is determined by the number of service requests is received by the subsystem. In this case, the cost of resources to ensure the functioning of the system is directly proportional to their number. The initial data defining characteristics of the modernized systems are presented in Table 1. 
Table 1. Characteristics of Modernized Systems $S=\left\{S_{i}\right\}, i=1 . .3$

\begin{tabular}{|c|c|c|c|}
\hline Indicator & $\begin{array}{c}\text { Application } \\
\text { Management }\end{array}$ & Incident Management & $\begin{array}{c}\text { Asset \& Configuration } \\
\text { Management }\end{array}$ \\
\hline Count of using cycles, $n_{i, 0}$ & 100 & 60 & 80 \\
\hline Resource effect, $\psi_{i, 0}$ & 0,5 & 0,4 & 0,6 \\
\hline $\begin{array}{l}\text { Resource amount, } \\
R_{i, 0} \\
\text { Planned count of using cycles, }\end{array}$ & 200 & 150 & 133,33 \\
\hline$n_{i}=\left\langle n_{i, \min } ; n_{i, \bmod } ; n_{i, \max }\right\rangle$ & $\langle 110 ; 140 ; 190\rangle$ & $<70 ; 80 ; 110>$ & $\langle 80 ; 90 ; 140\rangle$ \\
\hline resource effect function, $\left\langle a_{i} ; k_{i}\right\rangle$ & $<2,0 ; 0,1>$ & $<2,2 ; 0,11>$ & $<1,8 ; 0,14>$ \\
\hline
\end{tabular}

In accordance with the initial step of the method the fuzzy amount of resources $R_{i}$, required for each subsystem is calculated on the basis of the initial data. Based on them, the expected resource consumption is calculated. The results are presented in Table 2 and Figure 3.

Table 2. Characteristics of Modernized Systems $S=\left\{S_{i}\right\}, i=1 . .3$

\begin{tabular}{cccc}
\hline Indicator & Application Management & Incident Management & Asset \& Configuration Management \\
\hline amount of resources, ${ }_{i}$ & 293,30 & 216,70 & 172,20 \\
total amount of resources, ${ }^{2}$ & 682,22 & $R^{\text {req }}$ & 198,89 \\
\hline
\end{tabular}

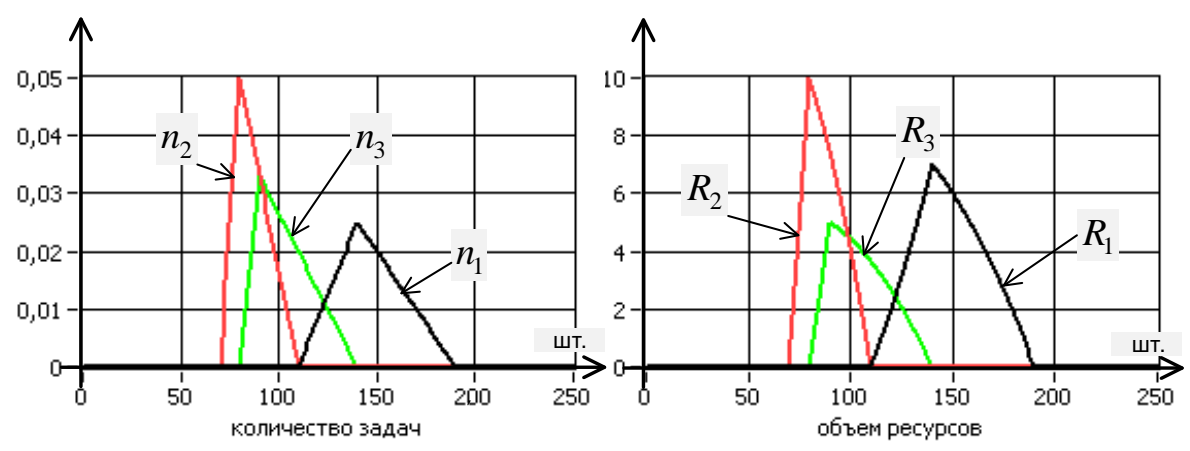

Figure 3. Fuzzy numbers of planned count of component using cycles (request for processes) and amount of resources

In according to the algorithm for the allocation of modernization resources by directions in Figure 2 the calculation was made. The results are presented in the Table 3. The task resource allocation was achieved by 5 iterations.

The presented calculations are explained in Figure 4, which shows the iterations of the algorithm to derivative resource intensity of the subsystem $S_{i}$ reducing function ${ }^{\prime}{ }_{i}^{\prime}$ and the final distribution of resources $g_{i}$ for the fifth iteration.

Application of the method to modernization of organization IT-infrastructure of the geodynamic monitoring system allowed determining the required amount and distribution modernization resources of between modernization directions. 
Table 3. The Calculation of Modernization Resource Allocation

\begin{tabular}{cccccc}
\hline indicator & Iteration 1 & Iteration 2 & Iteration 3 & Iteration 4 & Iteration 5 \\
\hline$h_{\text {min }}$ & 9,57 & 9,57 & 9,57 & 9,57 & 9,57 \\
$h_{\text {max }}$ & 137,10 & 74,69 & 51,54 & 45,90 & 44,40 \\
$\gamma$ & 2,76 & 4,29 & 4,95 & 5,17 & 5,25 \\
$h_{0}$ & 74,69 & 51,54 & 45,90 & 44,40 & 43,85 \\
$r_{1}\left(h_{0}\right)$ & 42,0 & 73,0 & 84,0 & 87,0 & 88,0 \\
$r_{2}\left(h_{0}\right)$ & 17,0 & 44,0 & 54,0 & 57,0 & 58,0 \\
$r_{3}\left(h_{0}\right)$ & 8,0 & 22,0 & 27,0 & 28,0 & 29,0 \\
$R_{M}=\sum_{i} r_{i}\left(h_{0}\right)$ & 67,0 & 139,0 & 165,0 & 172,0 & 175,0 \\
$g_{1}\left(h_{0}\right)$ & 63,27 & 90,88 & 98,54 & 100,50 & 101,10 \\
$g_{2}\left(h_{0}\right)$ & 20,32 & 43,64 & 50,40 & 52,28 & 52,89 \\
$g_{3}\left(h_{0}\right)$ & 16,04 & 36,48 & 42,17 & 43,24 & 44,27 \\
$\Delta R=\sum_{i} g_{i}\left(h_{0}\right)$ & 99,62 & 171,00 & 191,12 & 196,00 & 198,29 \\
$\Delta R-R^{\text {треб }}$ & 99,27 & 27,89 & 7,77 & 2,89 & 0,6 \\
\hline
\end{tabular}
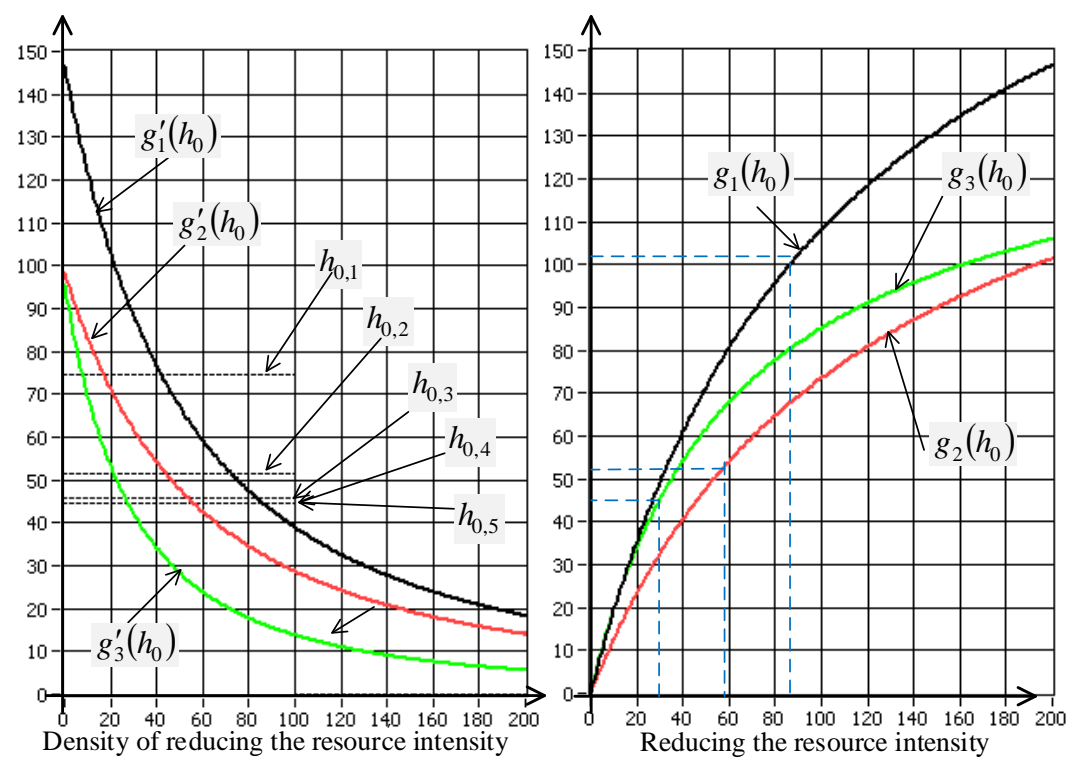

Figure 4. The graph of function of reducing the resource intensity and its density dependences by the amount of modernization resource

\section{CONCLUSION}

The paper proposes an approach to the selection of promising areas of modernization for geodynamic monitoring system $\mathrm{s}$ and the distribution between them resources allocated for modernization. The essence of the method is to use the assumption of achieving the maximum efficiency of allocated resources on improving the set of components of a monitoring system with equal marginal effects of reducing the resource intensity of their operation under conditions of using intensity uncertainty. The distribution algorithm based on the gradient method of rapid descent allows finding the optimal distribution of resources for a set of modernized in the planning period subsystems, with the minimization of the total amount of modernization resources. 


\section{REFERENCES}

[1] D. O. Derevinsky, "Methods of improving the efficiency of business process management on the basis of the theory of restrictions", proceedings of the St. Petersburg University of Economics and Finance, No. 4, P. 79-82, 2012.

[2] K. S. Myshenkov and A. N. Belyashov, "Methodologies, methods and models for analysis and design of control systems", Vestnik MGTU Stankin, № 3 (26), P. 76-82, 2013.

[3] B. V. Sokolov, et al., "Complex planning of modernization of information systems: methodological and methodical bases", Proceedings of spiiran, Vol.1, No. 3, P. 265-278, 2006.

[4] V. N. Volkova and V. N. Kozlov, (Ed), "System analysis and decision-making: dictionary-reference: Studies", the allowance for high schools, M.: Higher. SHK., 616 p, 2004.

[5] O. V. Loginovsky and Yu. A. Zelenkov, "On the methodology of strategic management of corporate information systems development in conditions of uncertainty", Bulletin of South Ural state University, Series: Computer technologies, control, radio electronics, Vol.13, No. 3, P. 83-91, 2013.

[6] O. V. Graeca and N. Ponomareva, "The conceptual construction of institutional structures in strategy process", news of southern Federal University, Technical science, № 5 (130), P. 221-226, 2012.

[7] V. I. Gurman, et al., "Method of improving management for hierarchical models of network structure", news of Irkutsk state University, Series: Mathematics, Vol. 8. P. 71-85, 2014.

[8] M.C. Lee, et al., "An Entropy Decision Model for Selection of Enterprise Resource Planning System", Int. J. of Computer Trends and Technology, March-April Issue, Pp. 162-169, 2011.

[9] J. Siswanto and A. P. Utomo, "ERP System Selection Model for Low Cost NGN Phone Company", Int. J. of Electronic Business Management, Vol. 6, No. 2. 3, Pp. 153-160, 2008.

[10] V. G. Totsenko, "About unification of algorithms of the organization of examinations", Problems of legal Informatization, №2 (12), P. 96-101, 2006.

[11] A.V. Grigoriev, et al., "Method of determination of values of weight coefficients taking into account competence of the involved experts", Property relations in the Russian Federation, No. 8, P. 73-83, 2004.

[12] S. K. Liang and C.T. Lien, "Selecting the Optimal ERP Software by Combining the ISO 9126 Standard and Fuzzy AHP Approach", Contemporary Management Research, Vol. 3, No. 2. 1, Pp. 23-44, 2007.

[13] B. D. Rouyendegh and T. E. Erkan, "ERP System Selection by AHP Method: Case Study from Turkey", Int. J. Business and Management Studies, Vol. 3, No. 2. 1, Pp. 39-48, 2011.

[14] M. Malinova, et al.,"An Empirical Investigation on the Design of Architectures Process", 11th International Conference on Wirtschaftsinformatik, 27th February-01st March 2013, Leipzig, German, Wirtschaftsinformatik Proceedings 2013. Paper 75. DOI:=http://aisel.aisnet.org/wi2013/75.

[15] D. A. Chistov, et al., "Ontological reengineering of business processes of Telecom operator", Management of large systems: proceedings, No. 33, pp 5-20, 2011.

[16] F. J. Duarte, et al., "BIM: A Methodology to Transform Business Processes into Software Systems", Software Quality. Process Automation in Software Development : Lecture Notes in Business Information Processing, Volume 94, pp 39-58, 2012.

[17] M. Benhima, et al., "Telco Business Process Transformation using Agile Lean Six Sigma and Frameworx components: focus on the core engineering aspects with a case study", International Journal of Computer Science Issues (IJCSI), Vol. 10, Issue 1, No 1, Pp 37-51, 2013.

[18] W. Jörgen, "Weibull Discounted-Value Representations of Temporal Preferences", Mathematics of Operations Research, Vol. 10, No. 2, Pp. 244-250, 1985.

[19] A.D. Ragulsky, "Historical review of the development of the theory of utility", Problems of regional economy, No. 17, P. 20-48, 2012.

[20] A. Gerber and K. Rohde, "Weighted Temporal Utility", Tinbergen Institute-tute Discussion Papers 13-167/1, Tinbergen Institute, September 26, 29 p, 2013.

[21] F. Tahriri, et al., "A review of Supplier Selection Methods in Manufacturing Industries", Suranaree J. Sci. Technol, Vol. 15, No. 2. 3, July-September, Pp. 201-208, 2008.

[22] V. P. Budovsky, et al., "Expert assessment of the area of permissible values of parameters of optimization of operating zones of control centers", New in the Russian power industry, No. 11, P. 6-16, 2005.

[23] C.C. Wei, et al., "An AHP-based approach to ERP system selection", Int. J. Production Economics, Vol. 96, Pp. 47-62, 2005.

[24] M. H. Damyad, et al., "Codify a trihedral inventory control model in terms of inflation in state of non-allowed shortage for an incorruptible commodity",UCT Journal of Research in Science, Engineering and Technology, 4(4), 13-21, 2016.

[25] K. Trupa, et al., "Formulation and Evaluation Nasal in Situ Gel of Rizatriptan", International Journal of Pharmacy Research \& Technology, 9 (2), 49-64, 2019.

[26] S. Monisha, et al., "An android application for exhibiting Statistical chronicle information", International Journal of Communication and Computer Technologies, 7 (1), 7-9, 2019.

[27] A. Tereso, et al., "An Automated Framework for the Integration between EVM and Risk Management", Journal of Information Systems Engineering \& Management, 3(1), 03, 2018.

[28] D. N. Dementiev, et al., "Algorithm of selection of perspective directions of modernization of control system of telecommunication network", Information systems and technologies, № 2 (88), P. 95-105, 2015. 